\title{
Screening for Antimicrobial Agents Producing Actinomycetes Isolated from Agricultural Soils in Hilla/Iraq
}

\author{
Iman Mohammad Jarallah* \\ *Babylon University/College of Science /Department of Biology
}

\begin{abstract}
Twelve agricultural soil samples were collected from different sites of Hilla city in Iraq . Out of these samples, 30 Actinomycetes isolates were isolated and purified in order to be tested for their antibiotics production ability . Primary screening exhibited there was one active isolate that posses antibacterial activity against four pathogenic bacterial species : Pseudomonas aeruginosa, Escherichia coli, Morganella sp. and Staphyloccocus aureus, in addition to antifungal activity towards two fungal species : Candida albicans and Candida glabrata. This active isolate was encoded as Streptomyces KGL-13, then it was identified by culturing on different International Streptomycetes Project media (ISP-1 to ISP-7 ) and characterizing by several biochemical tests.partial purification of antimicrobial substances was done using ethyl acetate (at ratio 1:1) and evaporated at $45^{\circ} \mathrm{C}$ to get pasty mass. The zone of inhibition (ZOI) diameter in mm of extract was determined on Muller Hinton agar. The results showed the highest ZOI happened towards E.coli and $P$. aeruginosa when gave $22 \mathrm{~mm}$ and $21 \mathrm{~mm}$, respectively. While it show a good activity against C.albicans, but it had less activity towards C.glabrata.
\end{abstract}

Key Words: Streptomyces, antimicrobial agents , primary screening

\section{Introduction}

Actinomycetes are gram positive, spore forming bacteria present in soil. They are characterized by their tough powdery, pigmented colonies. They are free living, saprophytic bacteria it considered as an intermediate group between bacteria and fungi. They are consisting of a major group of antibiotic producer and it play a role in recycling of organic matter[1]. A bout $80 \%$ of the total antibiotic production has been produced by streptomyces [2].

The members of streptomycetes are chemoorganotrophic, non fastidious microorganisms, so more simple synthetic media containing organic carbon source such as glucose, starch, sucrose, or lactate an inorganic nitrogen source $\left(\mathrm{NH}_{4}^{+}, \mathrm{NO}_{3}^{-}\right)$with some minerals can be used for their isolation. But to obtain a good growth can be cultivate on complex media containing oat meal, Yeast extract and malt extract [3]. The member of streptomycetes species consider as the most important medicines. They are the sources of antibiotics against bacterial and fungal infections, anticancer, transplant rejection and others [4].

Secondary metabolite production can be describe to symbiotic microorganisms only when synthesis has been distributed to the culture media, but the ability of streptomyces cultures to form antibiotics is not a fixed feature, so it can be greatly increased or completely lost under different conditions of nutrition and cultivation [5]. Therefore, the culture media composition together with the metabolic capacity of the producing organism greatly affects antibiotic biosynthesis [6].

The present study was done to screen biological activity of crude extract of Streptomyces species isolated from local soils in Hilla, Iraq.

\section{Materials \& Methods}

\section{- Soil samples:}

Twelve soil samples were collected from different sites in Hilla city, Iraq .All samples were taken from depth of the earth surface at $5-15 \mathrm{~cm}$. It was transferred to a laboratory by sterile small plastic containers. These soil samples were dried in electric oven at $60-65 \mathrm{c}^{\circ}$ for $3 \mathrm{hr}$., then stored at room temperature till examined.

\section{- Isolation of Actinomycetes from soil samples:}

Actinomycetes strains were isolated and obtained as pure cultures by using yeast -malt extract agar medium supplemented with $30 \mu \mathrm{g} / \mathrm{ml}$ chloramphinicol. In dilution plate technique, $1 \mathrm{~g}$ of soil sample was suspended in $9 \mathrm{ml}$ of sterile water and serial dilution was made up to $10^{-5}$. An aliquot $(0.5 \mathrm{ml})$ of suspension spread from the last dilution over the surface of starch casein agar medium and incubated at $30 \mathrm{c}^{\circ}$ fro $7-10$ days [7]. After period of incubation, the plates were examined for colonies of Actinomycetes, the typical colonies were purified by sub- culturing on Yeast extract - glucose agar plates and stored for further study[ 8].

The pure cultures of Actinomycetes isolates were screened for their antimicrobial activity against three types of pathogenic test bacterial species pseudomonas aeruginosa, Staphylococeus aureus, Morganella 
sp. and Escherichia coli in addition to two human pathogenic fungi:- Candida albicans and Candida glabrata. Perpendicular streaking technique was used for this purpose. The plates were incubated for $24 \mathrm{hr}$ at $37^{\circ} \mathrm{C}$ for bacteria, and $72 \mathrm{hr}$ at $25^{\circ} \mathrm{C}$ for fungi. After incubation period the clear zone growth of test bacteria and fungi beside the growth of isolate was considered as positive results for inhibitory activity [9].

\section{Identification of Actinomycetes isolates:-}

Cultural features such as color of aerial and substrate mycelium, pigmentation of selected active strains were examined on International Streptomyces Project (ISP) media [10]. The morphology of cellular shape of Streptomyces strains were tested by slide culture method[2] .The utilization of the mode of carbon sources was carried out due to methods of Gottlieb (1961)[11]. The ability of isolates to produce different enzymes was examined by using standard methods [12]. In addition to their ability to produce $\mathrm{H}_{2} \mathrm{~S}$, indole and melanin pigments.

\section{Fermentation broth for Antibiotics production:}

Loop-full culture of the Actinomycetes isolate was inoculated into conical flasks sterile starch casein broth medium under aseptic conditions. The culture flasks incubated at $28{ }^{\circ} \mathrm{C}$ for 7 days aerobically. After incubation period, the fermentation culture broth was filtered through sterile whatman filter paper No.1 aseptically. Then the filtrate broth was mixed with equal volume of ethyl acetate solvent. The organic layer was evaporated at $45^{\circ} \mathrm{C}$ till get pasty mass [13].

\section{Antimicrobial assay:}

The antibacterial and antifungal activity of the eight isolates was estimated in vitro by standard disc diffusion technique [14]. The discs $(50 \mu \mathrm{g} / \mathrm{disc})$ of extract were applied on the sterilized filter paper discs (5 $\mathrm{mm}$ in diameter ) in an a septic condition and allowed to evaporate the solvent in a septic hood for a few minutes . Erythromycin (30 $\mu \mathrm{g} / \mathrm{disc})$ and nystatin (30 $\mu \mathrm{g} / \mathrm{disc})$ were used as standard antibiotics for bacteria and fungi, respectively. The Petri dishes were incubated at $28^{\circ} \mathrm{C}$ for $24 \mathrm{hr}$. for bacterial growth and $72 \mathrm{hr}$. for fungi. The antibacterial and antifungal activities of the crude compounds were evaluated by measuring the respective zone of inhibition (ZOI) diameter in $\mathrm{mm}$.

\section{Melanin production:}

The color of the aerial and substrate mycelium of the isolates were examined on yeast extractglucose agar plate after 7 days of incubation at $30^{\circ} \mathrm{C}$. The pigment production was determined according to the national bureau of standards color chart [15]

\section{Results \& Discussion}

A total of 30 isolates of Actinomycetes were isolated from twelve local agricultural soil samples in Hilla city / Iraq. The colony forming units (CFU/g) were calculated by spreading method. The results showed the maximum number of colonies was $\left(8.6 \times 10^{7} \mathrm{CF} / \mathrm{g}\right)$ of soil which obtained from the cultivated sites (Table1). This high number may be return to richness of these soils with natural composts that loaded by nutrients and mineral salts needed for growing of these microorganisms.

Table (1): Numbers of Actinomycetes colonies per gram growing on ISP-2 of soil sites

\begin{tabular}{|l|c|c|}
\hline \multicolumn{1}{|c|}{ Collection site } & No. of colonies* & No. of Actinomycetes (CFU/g of soil) \\
\hline Alkarama (garden) & 80 & $8.6 \times 10^{7}$ \\
\hline Babylon university garden & 65 & $7.5 \times 10^{7}$ \\
\hline AL- jamiae park & 47 & $60 \times 10^{8}$ \\
\hline AL- Shawi City & 20 & $4.5 \times 10^{7}$ \\
\hline Hilla City center & 0 & 0 \\
\hline AL- Muhandisin & 0 & 0 \\
\hline AL- Muharbeen & 51 & $1.5 \times 10^{7}$ \\
\hline Forty street garden & 22 & $2.8 \times 10^{7}$ \\
\hline Sixty street garden & 38 & $3.9 \times 10^{7}$ \\
\hline AL- Iskan City & 42 & $4.8 \times 10^{7}$ \\
\hline
\end{tabular}

* Each value represents three replicates

Microscopic examination of Streptomyces KGL-13 showed typical filamentous structure with observed spore chains (Fig.1). Furthermore, colonies morphological characteristics showed green color of aerial mycelium, while substrate mycelium was yellow to brown in color when grown on ISP-4 (Fig.2 A and B). 


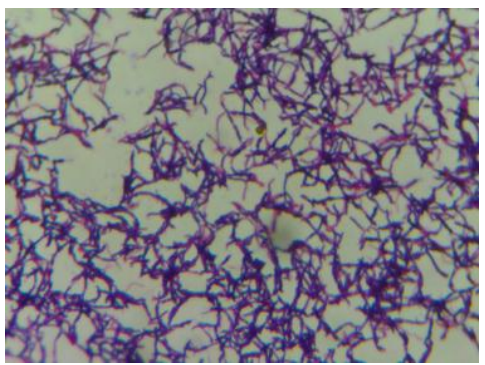

Fig.1. Microscopic features (1000X) of Streptomyces KGL-13
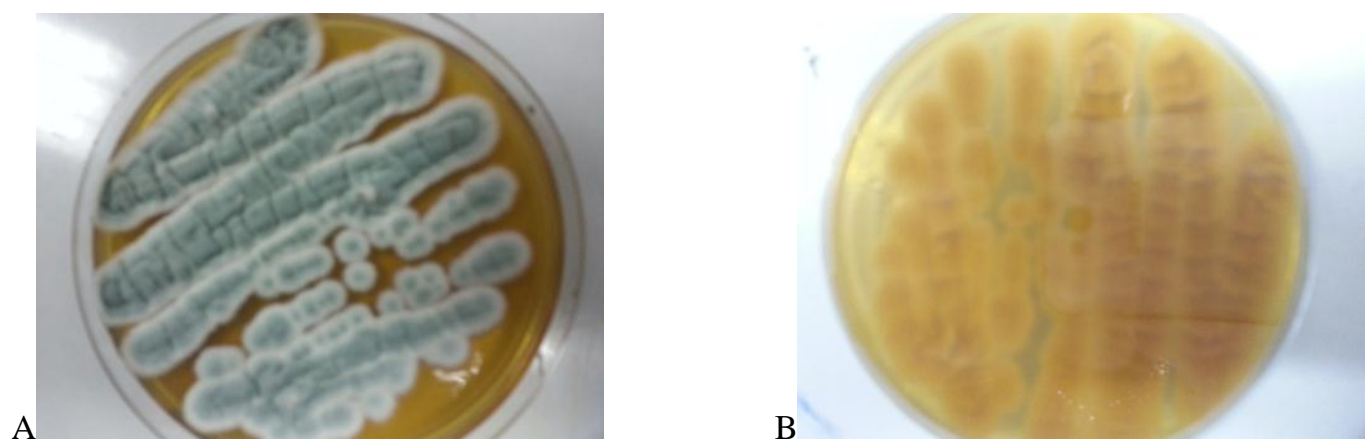

Fig.2.Morphological characteristics of Streptomyces KGL-13 grown on inorganic salts -starch agar (ISP4): A: aerial mycelium, B:substrate mycelium

The biochemical results of this isolate revealed it can hydrolyze starch and liquefy gelatin ,but it gave negative result for catalase, indole, oxidase, and $\mathrm{noH}_{2} \mathrm{~S}$ production (Table . 2). Furthermore, it was able to utilize all the used carbohydrate listed in table 3.

Table (2) : Biochemical tests of the strain Streptomyces KGL-13

\begin{tabular}{|l|c|}
\hline \multicolumn{1}{|c|}{ Biochemical test } & Result \\
\hline Gram stain & + \\
\hline Starch hydrolysis & + \\
\hline Gelatin liquefaction & - \\
\hline Methyl red & - \\
\hline Citrate utilization & - \\
\hline Catalase & - \\
\hline Licithinase & - \\
\hline Indol & - \\
\hline Voges proskaur & - \\
\hline Oxidase & $+(\alpha$-hemolysis $)$ \\
\hline Blood hemolysis & - \\
\hline Nitrate reduction & - \\
\hline
\end{tabular}

Table-3: Utilization of carbon sources by Streptomyces KGL-13 isolate

\begin{tabular}{|l|c|c|}
\hline \multicolumn{1}{|c|}{ Carbon source } & Result & Production* of yellow pigment \\
\hline D- glucose & + & ++ \\
\hline D- fructose & + & +++ \\
\hline Sucrose & + & ++ \\
\hline Mannitol & + & ++ \\
\hline Inositol & + & + \\
\hline D-arabinose & + & +++ \\
\hline D- xylose & + & +++ \\
\hline Sorbitol & + & + \\
\hline
\end{tabular}

The sign ((+++) mean strong production $\left({ }_{+++}\right)$mean good production, ((+)) weak production and ${ }^{(())}$ indicate no change.

The preliminary antibacterial assay of the isolates by perpendicular streak method exhibited that KGL13 isolate caused inhibition of test bacterial growth especially E.coli and P.aeruginosa ,but it was less active against Morganella sp. and S.ureus . On the other hand it caused disappearing of of C.albicans growth ,while it caused little inhibition of C.glabrata growth (Fig.3. A and B ).

This result similar to that obtained by Prashith et al., (2012)[16,17] who isolated Streptomyces isolate from Agumbe soils in India that able to depletion the growth of several bacterial and fungal species . 

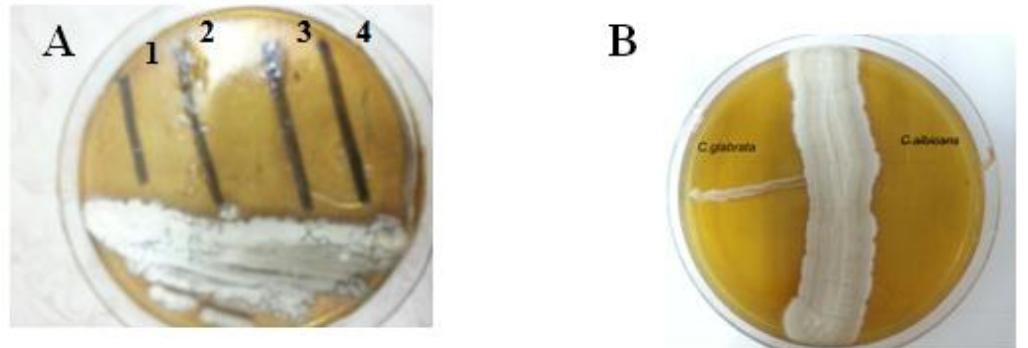

Fig.3.Primary screening of Streptomyces KGL -13 : A-against bacterial test organisms (1- E. coli, 2- P. aeruginosa, S. aureus, M. sp.). B : against two fungal species; $C$. albicans and $C$. glabrata

The active isolate was cultured on different types of ISP media in order to be identified (Table 4 ) . The results exhibited that this isolate belonged to Streptomyces sp. so it encoded as Streptomyces KGL-13.

Table (4): Cultural properties of Streptomyces KGL-13 strain (incubation period: 7 days, Temp. $^{2} 8^{\circ} \mathrm{C}$ )

\begin{tabular}{|l|l|l|l|}
\hline Medium & Growth & Aerial mycelium & $\begin{array}{l}\text { Substrate } \\
\text { mycelium }\end{array}$ \\
\hline Yeast-extract-malt extract agar (ISP2) & +++ & White & Yellow \\
\hline Oatmeal agar(ISP-3) & ++ & White & Light Gray \\
\hline Inorganic salts starch agar (ISP-4) & ++ & green & Yellowish brown \\
\hline Glycerol asparagine agar (ISP-5) & ++ & Yellow & Yellow \\
\hline Peptone-yeast extract iron agar (ISP-6) & - & - & - \\
\hline Tyrosine agar (ISP-7) & + & Brownish & Brown \\
\hline
\end{tabular}

The FT-IR spectrum of antimicrobial substances produced from Streptomyces KGL-13 isolate was showed absorbance at 3529-3468 cm-1 which refer to amine group, furthermore, there is sharp bond at 1687 cm-1 which attributed to ( $\mathrm{C}=\mathrm{N}$ ) bond ( fig .4 ). On the other hand, maximum absorption of uv spectrum was exhibited at 270-280 $\mathrm{nm}$ (Fig. 5 ). This result refer

to peptide antibiotic which exhibited maximum absorbance at wave length 210-230nm or 270-280nm[18]

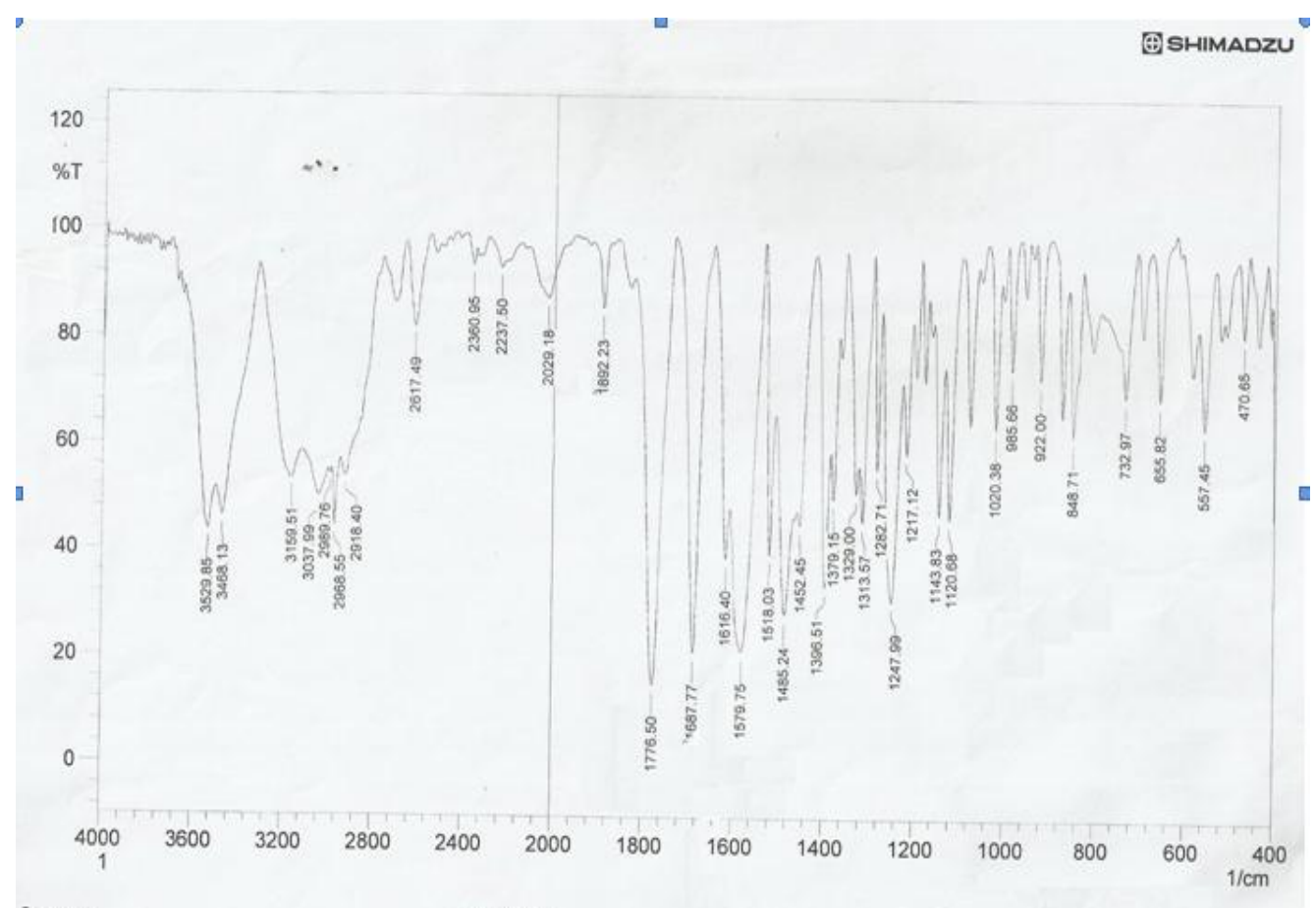

Fig.4.FT-IR spectrum antimicrobial substances produced by Streptomyces KGL-13 isolate 
Fig.5.UV spectrum of antimicrobial substances produced by Streptomyces KGL-13 isolate

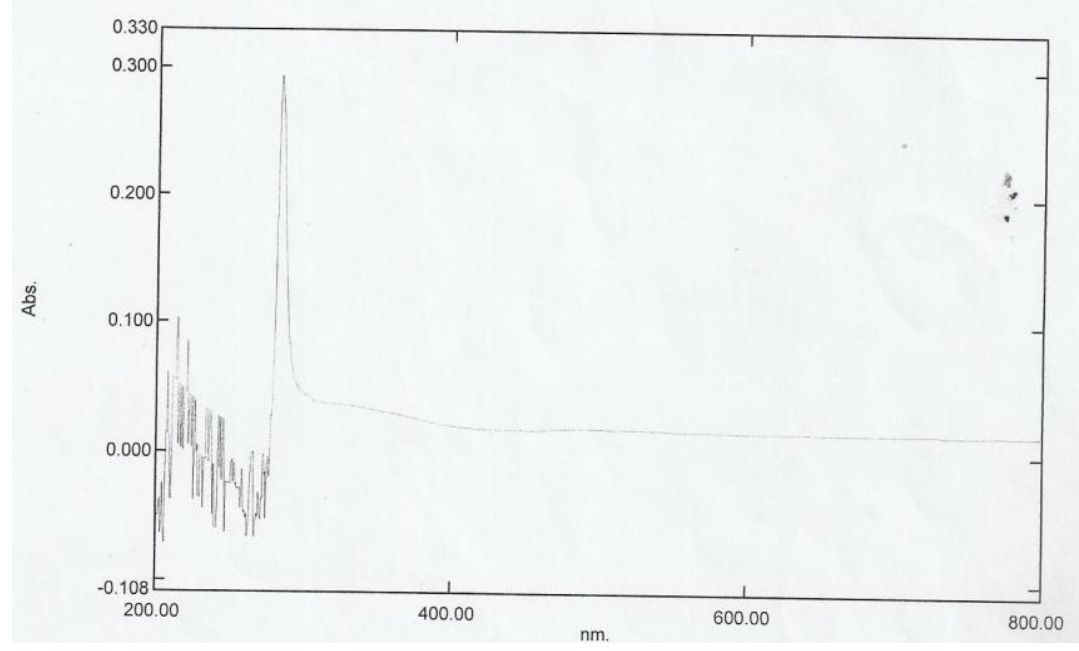

The antimicrobial activity of extract in terms of zone of inhibition (ZOI) were tested by disc diffusion method . The results exhibited that all the tested bacterial species (gram positive and gram negative species) showed a good sensitivity towards $(50 \mu \mathrm{g} / \mathrm{disc})$ but the highest activity was against E.coli and $\mathrm{p}$. aeruginosa that gave 22 $\mathrm{mm}$ and $21 \mathrm{~mm}$, respectively compared to $25 \mathrm{~mm}$ of erythromycin $(30 \mathrm{~g} / \mathrm{disc})$ as shown in(Table -5$)$.

Table.5.Antimicrobial activity of Streptomyces KGL-13extract

\begin{tabular}{|l|l|c|}
\hline Test organism & \multicolumn{2}{|c|}{ Inhibition zone diameter(mm) } \\
\hline Bacterial species & $22 \pm 0.1$ & 25 \\
\hline E. coli & $21 \pm 0.2$ & 25 \\
\hline p. aeruginosa & $15 \pm 0.2$ & 21 \\
\hline Morganella sp. & $17 \pm 0.3$ & 20 \\
\hline S.aureus & $19 \pm 0.2$ & Nystatin $(30 \mu \mathrm{g} / \mathrm{disc})$ \\
\hline Fungal species & $6 \pm 0.1$ & 18 \\
\hline C.albicans & 6 & 17 \\
\hline C.glabarta &
\end{tabular}

* $\mathrm{SE}=$ Standard Error

These results were resemble to many previous studies that included isolation of Streptomyce s species isolated from locally soils that potent significant antimicrobial activity towards several pathogenic microorganisims[19; $20 ; 21]$.

\section{References}

[1]. Unaogu, I. C., Gugnani, H. C. and Lacey, J. (1994). Occurrence of thermophilic actinomy- cettes in natural substrates in Nigeria Antonie van Leeu weenhock 65,1-5.

[2]. Williams, M.R , S.T.; F.L. Davies ; C.I. Mayfield and Khan. (1971). Studies on the ecology of actinomycetes in soil II. The $\mathrm{pH}$ requirements of Streptomycetes from two acid soils. Volume 3( 3) : 187-192.

[3]. Kavitha , A., M. vijagalakshmi, P. sudhaka and G. Narasimha (2010). Screening of Actinomycetestrains for the production of antifungal metabolotes. Afr. J. Microbiol. Res. 4(1): 27-32.

[4]. Rahman, M. A.; M. Z. Islam, and M. A. Islam. (2011). Antibacterial Activities of Aetionmycets isolates collected from soils of Rajshahi, Bangladesh. Biotech. Res. Int. 20: 1-6.

[5]. Wellington E.M.H, Cresswell. N. and He rrone P.R. (1992). Gene transfer between streptomycetes in soil. Gene 115. 193-198.

[6]. Hassan, M.A, M. Y. EL- Naggar and W. Said. (2001). Physiological factors affecting the production of an antimicrobial substance by Streptomyces violatus in batch cultures. Egypt. J. Biol. 3: 1-

[7]. Balagurunathan, R. Subramanian, A. (2001). Antagonistic streptomycetes from marine sediments. Adv. Biosci. 200: 71-76.

[8]. Biswas, M., A. Rahman, H. Katum and A. Islam. (2001). Isolation and characterization of streptomyces sp. ANBS-15 and Antimicrobial activities of its secondary Metabolities. Bang. Pharm. 14 (1): 15-20.

[9]. Haque, S. K., S. K. sen and S. C. pal. Antimicrobial spectra and toxicity of antibiotics from Streptomyces antibioticces sr 15-4. Indiam J. Microbiol. 36: 113-114.

[10]. Oskay M, Tamer AU, Azeri C. Antibacterial activity of some actinomycetes isolated from farming soils of Turkey. Afr J Microbiol Res 2004;9:441-6.

[11]. Gottlieb, D. (1961). An evolution of criteria and procedures used in the description and character rization of Streptomyces, A cooperative study. Appl. Microbiol. 9: 55- 60.

[12]. olding, A. J. Collee, J. G. (1971). Routine Biochemical tests. Methods Microbiol. 6: 1-31.

[13]. Gautham, S. A. Shobha, K. S. Onkarappa R. and Kekuda T. R.P. (2010). Isolation , chareterization and antimicrobial potential of Streptomyce species from western ghates of Karnataka, India. Res. J. pharm. Pharm. Tech. 5(2): 233-238.

[14]. AL- Bari, M. A., A., Bhuiyan, M. S. A., flores. M. E., petrosyan, p., Garcia -varela, M. and Islam. M. A. (2005). Streptomyces bangladechensis sp. Nov., isolated from soil, which produces bis- (2-ethylhexyl) phthalate. Int. J. sys. Evolut Microbiol. 55: 19731977. 
[15]. Zhao, H., L. parry, D.I. Ellis, G. W. Griffith and R. coodacre. (2006). The rapid differentiation of streptomyces is olates using fourier transform infrared spectroscopyes . Vibrational spectroscopy. 40 (2): 213-218.

[16]. Prashith ,K.T.;Shobha K.S.;Onkarappa ,R.; Goutham,S.A.and Raghavendra H.L.(2012).Screening biological activities of a Streptomyces species isolated from soil of Agumbe ,Karnataka,India.Inter.J.Drug Develop. \& Reaserch.4(3):104-114.

[17]. Shirling, E. B. \& Gottlieb, D. (1966). Methods for characterization of streptomyces species Int. J. system. Bacteriol. 16 (3): 313-340.

[18]. Kumar, A. ;Saini,P . and Shirvastava,J. N. (2009). Production of peptide antifungal antibiotics and biocontrol activity of Bacillus subtilis .Indian J. Exp.Biol.47:57-62.

[19]. Al-Hulu ,S ;Al-Charrakh ,A.H. and Jarallah E.M. (2011).Antibacterial activity of Streptomyces gelaticus isolated from Iraqi soils. Babylon Medical Journal 8(3):404-411.

[20]. A.H.Al-Saadi; Majid ,N. and E.M.Jaralla.(2013) . Isolation and Identification of Streptomyces from different sample of soils .JBMS.1:30-36.

[21]. Jarallah E.M. and Noor H.R.(2014).Extraction and purification of antimicrobial agent produced from Actinomycetes isolated from agricultural soils . J.Babylon.University. 22(2):749-758. 